\title{
Los desplazamientos forzados y la desterritorialización como experiencia traumática personal y transgeneracional
} Forced displacements and deterritorialization as personal
and transgenerational traumatic experience

\author{
Brisa Varela* \\ Universidad Nacional de Luján, Luján, Argentina \\ ISSN: ISSN-OI85-4259; e- ISSN: 2007-9I76 \\ DoI: http://dx.doi.org/IO.28928/ri/7620I4/atc3/varelab
}

\section{Resumen}

Este artículo presenta un estudio de caso referido a los desplazamientos forzados de mujeres armenias como sujetos históricos en situación de migrantes en contexto de genocidio. En el presente se encuentran nuevos contingentes "en viaje" de varones y mujeres armenios, los que que difieren de los flujos históricos en relación con el vínculo imaginado que formulan respecto a los nuevos espacios de asentamiento y a la (re)construcción de las identidades a partir de la transmisión transgeneracional.

Palabras clave: experiencia de las mujeres, desplazamientos forzados, genocidio, sobrevivientes

\section{Abstract}

This article presents a case study of the forced displacement of Armenian women in context of the genocide, looking at women as active historical subjects.

At present news these "travelling" groups, we find Armenian men and women who are different from the historical in relation with the imagined link which they formulate regarding the new space and the reconstruction of identities from trans generational transmission. Key words $¥$ experience of women, forced displacement, genocide, survivors

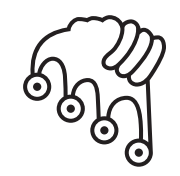

\section{IZTAPALAPA}

Agua sobre lajas

* Investigadora del Departamento de Ciencias Sociales, División Geografía, de la la Universidad Nacional de Luján, Argentina.

brivarela@yahoo.com.ar 


\section{Introducción}

Anjulio del 2003 participé de un encuentro con Anie Kalaiyjian en Buenos Aires
Anie es miembro de una familia armenia cuyos antepasados fueron víctimas
de crímenes masivos y luego formaron parte de contingentes de desplazados. En la actualidad es miembro de la Sociedad Internacional de Psicotrauma y trabaja con sobrevivientes turcos y armenios en lo que hace a la trasmisión transgeneracional del trauma. Durante la conversación sostuvo que el hecho más traumático de su vida sucedió antes de su nacimiento.

En este trabajo proponemos al lector reflexiones sobre cuestiones que hacen a la violación de los derechos humanos, en procesos políticos asociados con desplazamientos forzados y desterritorializaciones a los que se ven sometidas las poblaciones civiles, en contextos de violencia extrema. La problematización que nos ocupa se relaciona no sólo con los efectos materiales y psíquicos de los desplazamientos forzados sobre mujeres y niñas que sufrieron las acciones en forma directa, sino sobre aquellas que, aun no habiendo vivido los episodios de violencia, reciben su impronta a través de procesos de transmisión inter y transgeneracional.

El objetivo que guía este texto es abordar el caso armenio, considerándolo como especialmente interesante ya que permite realizar un seguimiento a lo largo de tres generaciones, $y$ tomarlo como matriz para considerar casos similares que se desarrollan en el presente. Si bien no hay dos casos exactamente iguales, el análisis podría tenerse en cuenta para diseñar acciones en el marco del Derecho Internacional Humanitario y la Protección de la Población Civil en los Protocolos Adicionales al Cuarto Convenio de Ginebra (1949). Fundamentalmente se apunta a la necesidad insoslayable de la actuación estatal en las distintas etapas que permita apuntalar la (re)territorialización y la reconstitución identitaria de la población desplazada violentamente.

Desde el punto de vista metodológico consideramos tres ítems: en el primero se presentan aproximaciones conceptuales; en el segundo, un panorama del contexto 
histórico y la explicitación de la experiencia traumática de sucesos vividos por mujeres y niñas. La reconstrucción se realiza a partir de fuentes históricas de carácter testimonial, publicadas en recopilaciones documentales.

La mirada remitirá a esa experiencia histórica traumática vivida por las mujeres como víctimas y a las huellas materiales y psíquicas que se estructuraron en situaciones límite.

En un tercer ítem se propone un acercamiento a las vivencias que, en la actualidad, tienen las descendientes de aquellas desplazadas; en este caso se recurrirá a entrevistas orales que he realizado en Buenos Aires y material documental fílmico. Se entretejen los aspectos teóricos-conceptuales derivados de una mirada psicoanalítica con aquellos derivados de la práctica social.

\section{Aproximaciones conceptuales}

Hacia la segunda década del siglo pasado, la Argentina recibía uno de los últimos contingentes de desplazados forzados del siglo anterior. Se trataba de varones y mujeres inmigrantes armenixs que escapaban del genocidio llevado adelante por el Imperio Turco a principios del siglo xix. Fueron numerosas las mujeres que integraron esos contingentes y que luego organizaron familias cuyos descendientes forman hoy parte de la sociedad argentina (Varela, 2009).

Durante mucho tiempo los geógrafos habían ignorado la presencia específica y particular de las mujeres en la producción de territorio, presentando la experiencia de los hombres como si ésta fuera la totalidad de la experiencia humana (Monk y Hanson, 1989). Desde esa mirada, las mujeres que formaban parte de una masa anónima e ignorada, fundamentalmente eran presentadas como sujetos pasivos en diversas situaciones tales como en los flujos migratorios, desplazamientos, en el ámbito de la producción o en la construcción de paisajes rurales o urbanos, entre otras cuestiones. Situarse en una perspectiva feminista crítica, que remite a generar una mirada resistente a las asignaciones tradicionales de roles de género en el marco del patriarcado, significa visibilizar y valorizar la acción de los diversos colectivos de mujeres en la producción de espacio geográfico.

Hablar de "género" implicará hacer referencia no a una categoría biológica que se identifica con el sexo, sino incorporar al estudio aquellos aspectos culturales como valores, normativas, representaciones sociales, etc. con las que se visualiza socialmente a los varones y mujeres. En suma, representa la "carga cultural" colocada sobre ellos y lo que socialmente se espera y reconoce como positivo o negativo para cada uno según 
"corresponda", dependiendo siempre de las épocas y culturas de que se trate, pero siempre enmarcadas en el sistema patriarcal. Las geografías de género se producen deconstruyendo la geografía tradicional desde el clivaje de la teoría crítica y del posmodernismo. En esta perspectiva, el espacio geográfico no es neutro, sino el resultado de relaciones de poder, de clase, étnicas, religiosas, generacionales y de género. El análisis geográfico requerirá, por lo tanto, incorporar la diversidad de la experiencia humana en circunstancias de asimetría de poder, y el acceso a la producción de espacio se entiende como medio de control social y político (Lindón y Hiernaux, 2010).

En este estudio nos remitimos al momento en el que se consolida el Estado-nación moderno a fines del siglo xix y principios del xx; en ese contexto histórico y en un proceso de acción y reacción, el nacionalismo turco y el armenio se retroalimentan, encontrándose este último en inferioridad de condiciones militares. Los intentos de consolidar el estado moderno turco en momentos en que se hacía evidente el derrumbe del esquema imperial teocrático, exigían la redefinición territorial en función de parámetros diferentes a los dinásticos de los sultanatos y también de una homogeneización poblacional en términos de constituir una nación que respondiese a ese Estado territorial sin reparar en los medios. Ya fuesen las comunidades indígenas en América Latina o las minorías étnicas en Turquía, el objetivo era similar: obtener una soberanía estatal sobre un territorio, que debía sostenerse bien con la aceptación por parte de las otras nacionalidades o bien con su expulsión o exterminio.

Elementos tales como la continuidad territorial y la homogeneización de la población étnica y lingüísticamente, fueron considerados condiciones centrales en el proceso de conformación de los Estados decimonónicos. El arrasamiento de grupos étnicos que pudiesen perturbar la unidad fue entonces una práctica reiterada y legitimada.

Muchas víctimas de las acciones escaparon de los territorios que habitaban y formaron parte de una diáspora. Esta palabra de origen griego y significa dispersión. El estudio de las "diásporas" como fenómenos sociales implica abordar lugares comunitarios-identitarios, espacios interconectados a diferentes escalas, flujos de personas, bienes e ideas y la remisión a un espacio territorial de la memoria. Al igual que a otras nociones conceptuales trabajadas por diferentes disciplinas del campo social y en redefinición, se le asignan múltiples significaciones. No existe un acuerdo entre los autores sobre su uso, y muchos la aplican, sin especificar exactamente su significado, a cualquier movimiento de población o, en ocasiones, la limitan exclusivamente a las migraciones forzosas. Desde una mirada geográfica, Bruneau (1994) afirma que una diáspora es lo opuesto a un Estado-nación que se caracteriza por estar bien definido, bien delimitado, y centralizado. Una diáspora, desde el punto 
de vista territorial, forma parte de un organismo extremadamente descentralizado, policéntrico, con límites muy fluidos y mal definidos. Sus comunidades son como células unidas entre sí por diversos tipos de flujos. Incluyen dos niveles superiores de organización: el nivel nacional del país de recepción y el nivel mundial, más o menos limitado por el país de origen, si es que existe.

En relación con el objeto de estudio, partimos de reconocer en nuestro tratamiento de la diáspora de las desplazadas, la existencia de un origen traumático en el grupo, asociado con conflictos graves que pueden entrañar persecuciones políticas, genocidios, expulsiones en masa y una decisión colectiva de preservar emblemas y símbolos identitarios y de referenciarse en un territorio mítico. La relación con el espacio "de origen" está cargada de memoria y emocionalidad. La identidad remite a la invocación de los antepasados, a la delimitación de un territorio identitario y a la reivindicación por el grupo del ejercicio del poder sobre un espacio identitario idealizado.

Desde el punto de vista conceptual, se focaliza en el significado de la trama generacional en el proceso de elaboración, transmisión y continuidad/ruptura de la identidad étnica y la ideología nacionalista. La relación entre identidad nacional/ espacio - dada con un ámbito territorial específico- se amplía y complejiza con la relación identidad nacional/tiempo referida a las continuidades y rupturas en las valorizaciones de un grupo (Pellegrino, 1983) en el proceso de transmisión generacional ${ }^{1}$. Pierre Nora (1984) ha propuesto asimismo aplicar en los estudios históricos la noción de generación vinculada a la transmisión de los saberes y experiencias no como actos individuales sino como producciones de la memoria colectiva. Una reflexión pertinente a nuestro caso de estudio tiene que ver con las características particulares en que se produce la transmisión generacional de los aspectos traumáticos vividos (Grinberg y Grinberg, 1996:22): genocidio, migración forzada e inserción en la Argentina.

La búsqueda de herramientas que permitan trabajar sobre los mecanismos de la memoria en situaciones límite, en las que un grupo humano es objeto de políticas de exterminio planificadas, hizo que algunas líneas historiográficas apelaran a la

1 Pellegrino al trabajar la transformación del espacio y la identidad cultural, propone considerar la distinción entre "espacio de pertenencia" y "espacio de referencia". En tanto que el primero se relaciona con "la ocupación de un territorio y la posición de un actor social y la inscripción de su grupo de pertenencia en un lugar; el segundo remite al espacio de las valorizaciones y desvalorizaciones del espacio de pertenencia”. Pellegrino, G. y otros (1983:27) . 
categoría de trauma social, procedente de categorías del psicoanálisis, para referirse a aquello concebido como "lo inenarrable" de este tipo de experiencias.

Esta inenarrabilidad alude a "ilustrar la naturaleza indecible tanto de nuestras experiencias históricas de catástrofes colectivas como de nuestras representaciones de las mismas" (Mudrovcic, 2003:III). Sin embargo, las nociones psicoanalíticas del concepto de trauma no trabajan desde la dinámica social de la memoria colectiva, sino sobre la memoria individual de las personas y su transposición no es una tarea sencilla ni exenta de complejidades que cuestionan el uso concreto del concepto.

La noción de trauma es ya introducida por Freud en su I8 Conferencia "La fijación al trauma, lo inconsciente" y en la 24 Conferencia "El estado neurótico común"; ambas corresponden al período 1916-1917. Freud intenta pensarlo articulando lo individual con lo colectivo en situaciones históricas, explicará que:

La analogía más inmediata con esta conducta de nuestros neuróticos la ofrecen enfermedades como las que la guerra provoca ahora con particular frecuencia: las llamadas neurosis traumáticas. Desde luego también antes de la guerra las hubo, luego de catástrofes ferroviarias y otros terribles peligros mortales. [...] Las neurosis traumáticas dan claros indicios de que tienen en su base una fijación al momento del accidente traumático. Estos enfermos repiten regularmente en sus sueños la situación traumática como si ella se les enfrentara todavía a modo de una tarea actual insoslayable. [.... Mas: la expresión "traumática" no tiene otro sentido que ese, el económico. La aplicamos a una vivencia que en un breve lapso provoca en la vida anímica un exceso tal en la intensidad de estímulo que su tramitación o finiquitación por las vías habituales y normales fracasa, de donde por fuerza resultan trastornos duraderos para la economía energética. (Freud, 2001:25).

Desde la perspectiva de Freud, recordar es la posibilidad de organizar una secuencia narrativa, dando sentido lógico a lo que anteriormente podría aparecer como una serie de eventos aislados.

La elaboración de las experiencias traumáticas relativas a las guerras en sus distintas formas implica, además de un esfuerzo psíquico, el reconocimiento e instalación en el cuerpo de esas emociones, como claramente lo expresa Alicia Lindón (2012:70I).

Desde este campo del saber, aún en proceso de hacerse, se observa una asignatura más o menos pendiente: el reconocimiento de que el sujeto, con su corporeidad y emociones, también habita lugares que se hacen parte de lo social, del cuerpo que 
allí está y de las emociones experimentadas por dichos cuerpos. En otras palabras, los estudios más consolidados sobre el cuerpo, la corporalidad y las emociones suelen olvidar la espacialidad, aunque paradójicamente la relación entre el cuerpo y el espacio es inevitable para la condición humana. De igual forma, la relación entre las emociones y el espacio constituye otro aspecto ineludible de la vida misma.

El cúmulo de emociones colocadas en el alma y en el cuerpo de las mujeres desplazadas en contextos de violencia, podrán ser, a lo largo de sus vidas, elaborados o encriptados. No obstante, en ambos casos se trasladarán a la psique de uno o varios miembros de las generaciones siguientes. Las características con las que se realizan este tipo de transmisiones psíquicas han sido objeto de estudio en especial por la escuela francesa desde la década de los setenta; volveremos sobre este tema y sus implicancias para el caso que exponemos, en el último punto de este escrito.

Tapia Paniagua y Pérez Veléz (20II) han abordado la transmisión transgeneracional, enfatizando que en la herencia psíquica de las personas es importante distinguir tanto lo intergeneracional (lo aprendido directamente de los padres), como lo transgeneracional, que consiste en la adquisición de una información construida en generaciones previas, ${ }^{2}$ y que es expresada por un miembro de una generación posterior a manera de un síntoma, del cual no se encuentra una explicación lógica. De esta manera, en el sujeto se produciría una identificación inconsciente alienante procedente de un fantasma, que suscita fantasías y provoca identificaciones en uno o varios miembros de la familia. Estas autoras sostienen que los objetos psíquicos inconscientes familiares pueden ser "transformables" o "no transformables".

Los objetos transformables constituyen la base de la materia psíquica que las familias trasmiten a sus descendientes de generación en generación (intergeneracional). Los objetos no transformables permanecen enquistados, incorporados e inertes y de manera inconsciente son tomados a través de un pacto denegativo por uno o varios miembros de una generación posterior (transgeneracional). (Tapia Paniagua y Pérez Vélez, 20II:48)

2 En estos casos algunos psicoanalistas han tomado el término de telescopaje propuesto por Haydée Faimberg, quien entiende este concepto como el proceso, las vías y los mecanismos mentales capaces de operar transferencias de organizaciones y contenidos psíquicos entre distintos sujetos y, particularmente, entre generaciones, 


\section{Historia de oscuridades}

La migración de las mujeres armenias se insertó en un movimiento general que incluyó a personas de ambos sexos y de todas las edades y que se produjo a escala internacional en diversas fases. Las descripciones de estos sucesos han sido denunciadas en el momento que se producían a autoridades de países extranjeros. Los testimonios históricos utilizados pertenecen en su gran mayoría a mujeres occidentales que se encontraban en territorios del Estado turco ejerciendo su profesión - especialmente en el caso de enfermeras, educadoras y religiosas- como viajeras o bien acompañando a sus esposos.

Las descripciones que les pertenecen son de gran importancia en tanto no hay un prejuicio o previo compromiso político con alguno de los actores enfrentados. Si se realiza una lectura atenta del discurso, es posible sistematizar los datos y pueden extraerse conclusiones claras de lo que fue la política expresamente decidida, la metodología utilizada para concretarla y las responsabilidades específicas por parte del Estado.

Algunos conceptos centrales permiten comparar las descripciones y obtener datos que se reiteran y permiten sistematizar y categorizar con claridad los sucesos producidos.

Las primeras órdenes de abandono de las viviendas y de expulsión se hicieron recaer sobre la totalidad de la población armenia incluyendo varones y mujeres de diferentes generaciones -incluyendo desde ancianos a niños lactantes.

La población para ser deportada fue agrupada en "campos de concentración" mayormente al aire libre y que podían ubicarse desde en las plazas centrales de las ciudades a -mayoritariamente- en las afueras de la ciudad. Las condiciones de estos campos fueron infrahumanas: los prisioneros no contaban con alimentos, agua, letrinas ni posibilidad de protegerse de las inclemencias climáticas; esta situación, sumada al impacto psicológico y a la política de terror, llevó a muchos/as a la locura, la enfermedad, epidemias y muerte.

El campamento de Islahié es la cosa más triste que yo jamás haya visto. Justo a la entrada estaban tirados un montón de cuerpos sin enterrar. Conté 35 y en otro lugar 22, en la inmediaciones vecinas a las tiendas de aquellos que habían caído en virulenta disentería. La suciedad dentro y alrededor de estas tiendas era algo indescriptible. En un sólo día el comité de entierro sepultó a 580 personas (Schafer, 1915ः389). 
En pocas horas las mujeres, junto con lxs ancianxs y niñxs ${ }^{3}$, eran separadas de los hombres adultos. A estos últimos se los ataba y preferentemente por la noche, amparándose en la "invisibilidad", se los asesinaba utilizando diversas metodologías - fusilamientos y asesinatos con armas blancas, despeñamientos atados desde montes. Una vez separados los varones de las mujeres, y quedando éstas absolutamente desprotegidas, se ejercían sobre ellas permanentes violaciones a sus derechos elementales "Las familias eran dispersadas, los hombres asesinados y las mujeres y jóvenes entregadas a los turcos, los niños vendidos para convertirlos en musulmanes" (Holt, 1915: 302).

A las violaciones de los derechos específicamente ejercidas sobre los varones - detención, torturas y asesinatos- se agregaron aquellas que específicamente tuvieron como objeto a las mujeres. Ellas fueron marchas forzadas por el desierto sin alimentos, sin protección del sol y sin agua. Violaciones sexuales permanentes y reiteradas sobre mujeres y niñas. "Ser mujer, en especial una mujer atractiva, con todos los peligros que acechan a una mujer, algunas en Constantinopla me dijeron que desfigurarían sus rostros si fuesen exiliadas" (Ibid.).

Obligación de marchar en avanzados grados de gravidez y en el posparto inmediato, provocando la muerte de las madres y los bebés, aparecen repetidas en diferentes testimonios.

Entonces en un carro recorrí toda la ruta a Islahie. Si había visto mucha angustia antes, las escenas que veía allí desafían toda descripción. Una mujer de débil complexión estaba sentada junto al camino con un cojín sobre la espalda y un bebé atado encima y en sus brazos llevaba a un niño de dos años; sus ojos estaban turbados y se encontraba en sus últimos jadeos. La mujer había caído en la angustia y lloraba de modo desgarrador. La llevé conmigo hasta el próximo campo de concentración donde el niño murió (Schafer, 1915ः 389)

Era 1918, cuando los turcos entraron en Kars, se le ordenó a toda la población de la ciudad y las aldeas cercanas que salieran de sus casas, y en caso de desobediencia, se los amenazaba con ser asesinados. La gente salió a las calles, principalmente mujeres y niños. Se reunieron cerca de la carretera que conduce a la ciudad más cercana Gyumri. Cientos de personas buscaban la manera de cruzar el río por un puente de Kars de apenas un metro de ancho. Cuando los turcos comenzaron a disparar

3 En éste y en los subsiguientes casos donde a aparece una " $\mathrm{x}$ " sustituyendo a una vocal se respetó la grafía del autor. 
sobre las personas desarmadas, muchas de ellas se arrojaron al agua. Vi a dos mujeres jóvenes que saltaron al río con sus hijos. El primer muerto que distinguí era un niño pequeño. Se cayó, y su madre, alzando su camisa ensangrentada, comenzó a gritar y gritar (Abrahamian, 2010).

A estas características se agregaron: asesinatos cuando se negaban a marchar, raptos de niñas para ser prostituidas o incluidas en los harenes, conversiones forzadas al islam, saqueos y robos de las pocas pertenencias que llevaban.

En estas instancias se puso en práctica la violación sistemática de las mujeres como estrategia de acción de imposición racial deliberada, con el objetivo de embarazarlas de niños turcos. Varias de las ancianas entrevistadas hacen alusión a esta realidad y plantean que muchos de los casamientos arreglados por sus padres tenían por objeto "buscarles un esposo que las protegiera de las violaciones". Esta situación es una característica que se reitera permanentemente en acciones militares recientes y que sitúa históricamente a la mujer en el lugar de objeto de dominación sobre ella y sobre el varón visto como "dueño".

Dentro de ese contexto la política del Estado turco no fue neutral en relación con el origen étnico, la religión y el género. Las mujeres armenias del común -más allá de la acción de heroínas consagradas luego por la literatura popular del exiliodesarrollaron formas de resistencias activas y pasivas cuyos contenidos y formas sólo pueden captarse en todo su dramatismo en el contexto histórico de un genocidio.

Los gendarmes la intimaron a que debía partir en algunas horas, ella fue nuevamente a la Casa de Gobierno. Fue en vano; le dieron dos camellos para ella, los niños y el equipaje. Bajo el sol abrasador de Osmanieh nació un cuarto hijo y cuando arribó a Alepo con el niño muerto, lo único que pudo hacer fue dirigirse al hospital (Cold, 1915:405).

Uno se entera porque ellos mismos lo cuentan, que muchas mujeres arrojaron sus hijos al río ya que no tenían medios de nutrirlos y prácticamente todas las familias se vieron disminuidas entre los hombres que fueron asesinados (Atkinson, 1918: 374).

A diferencia del Estado Nazi, que explicitó la política de exterminio en diversa documentación y lo asumió públicamente como un valor a sostener, el estado manejado por los Jóvenes turcos mantuvo las acciones sistemáticas y organizadas en el marco del ocultamiento y la negación pública. Esto llevó también al intento del ocultamiento de los cuerpos de lxs asesinadxs, así que podríamos mencionar entonces la 
puesta en práctica de la “desaparición de personas". En el genocidio armenio pueden reconocerse elementos que las autoras feministas mencionan para el nazismo en el sentido de que la "guerra racial" se centró en las mujeres como un elemento de singularidad del genocidio nacionalsocialista del pueblo judío (Bock, 1993).

Por último, hay que destacar la funcionalidad asignada a los lugares, identificando los "lugares" de la muerte y la vida en los que se desarrolló esta historia y la forma en que fueron percibidos, cargados de contenidos y diferenciados a partir de los testimonios. Los territorios bajo dominio turco se caracterizaban por formar parte de un extenso espacio rural -recorrido por pastores de cabras y ovejas y con producción agrícola y de frutales en las áreas periféricas a las aldeas. Las aldeas cuyo origen se remontaba habitualmente a etapas muy antiguas, se ubicaban a orillas de cursos de agua y se constituían en centros de intercambio local y regional. Asimismo constituían el asiento de artesanos del cuero y textiles, de comerciantes, de autoridades civiles y funcionarios militares. Conservaban aún los muros que las diferenciaban y protegían del espacio exterior, la pertenencia a tal o cual ciudad-aldea será reconocida aún en la diáspora - por ejemplo las casas de los descendientes de Hadjin o de Marash. Los pobladores se reconocían sin la utilización de apellidos; dentro de estructuras premodernas, la identidad la daba el ser "hijx de "o "hermanx" o bien definidos por sus actividades y oficios, al estilo del medioevo europeo. Las historias familiares se encontraban arraigadas desde años en la aldea. Si bien los testimonios dan cuenta de la existencia de "barrios étnicos", también se observa la interacción entre los distintos pobladores; fue seguramente la pertenencia a diferentes religiones y diferentes pautas matrimoniales las que mantuvieron separados a los armenios -cristianos- del resto del universo islámico.

Sobresaliendo sobre todas las aldeas, la gran capital Constantinopla, sede del gobierno imperial, las actividades financieras, los bancos y el gran comercio, no fue prácticamente afectada por los sucesos e, incluso, se la intentó mantener al margen en tanto los mismos fueron ocultados al conocimiento europeo.

El Imperio turco ejercía, en especial a partir de las reformas, un dominio de la territorialidad, y la organización de un espacio. A partir de los testimonios utilizados pueden reconstruirse las funcionalidades dadas a los distintos espacios en el holocausto y las acciones específicas ejercidas en ellos.

a) En los centros urbanos, lugares del contacto cultural cotidiano entre los pobladores turcos y armenios, ellas fueron:

- Reclutamiento de varones para la realización de trabajos forzados en caminos y obras públicas. 
- Detención masiva de los varones líderes religiosos, políticos e intelectuales en un principio, y detención masiva a posteriori.

- Instalación en ellos de centros clandestinos de detenciones y tortura en prisiones, sótanos o, en varios casos, utilizando las iglesias ortodoxas, previo asesinato de los ministros religiosos.

- Confiscación de bienes muebles e inmuebles.

- Deportación masiva de ancianos/as mujeres y niños rumbo a un incierto destino.

- Las ciudades fueron también los espacios donde negociar la vida a cambio de: dinero o joyas, conversiones al islam, protección por parte de instituciones extranjeras e internacionales (Cruz Roja, Orfanatos, iglesias protestantes) y en algunos casos, como en Van, el lugar de la resistencia.

b) Las zonas fronterizas y rurales periurbanas fueron, habitualmente, los lugares en los que se ubicaron los campos de concentración de tránsito hacia un viaje sin destino fijo conocido. La concentración de población en estado de crisis emocional y sometida a vejámenes e inanición convirtió estas zonas en lugares de muerte en especial de los niños y las mujeres, ya que los varones eran asesinados por separado bajo el amparo de la nocturnidad.

Estas áreas rurales fueron en algunos casos el lugar del ocultamiento y la huida -entre los campos cultivados.

c) Las rutas de escape centradas sobre todo en las vías del ferrocarril atestadas de pasajeros y que se constituían en prácticamente única vía de salida del infierno.

Los vagones y estaciones fueron, sin embargo, también el lugar de concentración de las deportadas sin agua ni alimentos, sufriendo epidemias y enfermedades. Los trenes fueron también los lugares del filicidio y el suicidio femenino, ante la angustia de la crueldad y el sufrimiento, que llevaban a cabo cuando los ferrocarriles atravesaban precipicios.

d) El desierto, atravesado por los circuitos de caravanas de las deportadas, era un espacio signado específicamente como el espacio de la muerte. Las rutas del desierto eran los sitios preferidos para ataques y violaciones realizados por las tribus kurdas sobre las mujeres y niñas. Bordeando las aldeas, los itinerarios del traslado forzoso jalonado de etapas y de puntos fuertes en las ciudades a las que nunca se arribaba componen el lugar de "sentido único" un "espacio" que será recordado -junto con el de las masacres masivas en las ciudades-como el destino propuesto para la "solución final" y donde fueron mujeres y niños/as las principales víctimas (Varela; 2009 ). 
"Ciertos lugares no existen sino por las palabras que los evocan" dirá Marc Augé (1996;99). En este caso el desierto está por definición sobrecargado de sentido, es el sentido del desamparo, de la no vida, de la muerte.

\section{Un presente en claroscuro}

Muchas mujeres sobrevivieron al genocidio, abandonaron las tierras que les traían los ecos de la muerte, e iniciaron su desplazamiento en el largo camino de la diáspora. "Cada uno de ellas traería en sus maletas una mezcla de sentimientos: ansiedad, tristeza, dolor y nostalgia por un lado, junto con las expectativas e ilusiones esperanzadoras por el otro" (Grinberg, L.y Grinberg, R., 1996ः 2I). La imposición de la partida y la imposibilidad del retorno, sin duda condicionaron fuertemente a las primeras generaciones, la identidad en crisis debería ser reconstruida colectiva y artesanalmente en el exilio. Ellas se hallaron frente a la necesidad de invención de nuevas prácticas, ya que debieron enfrentar un espacio social que tensionó entre integrarse o mantener los patrones generacionales y culturales; entre mantener la memoria opresiva sobre situaciones traumáticas o desplegar estrategias que sin olvidar puedan convertir la memoria en un lugar vivo desde donde pivotear y reinstalarse en el presente.

Nos interesa tomar este proceso, de genocidio y desplazamiento forzado, como el punto de partida fundante de la diáspora y entendido como "vínculo integrador" desde la perspectiva tomada por Weber (Ricoeur, 1994:218), entendiendo que el tipo de vínculo formulado socialmente es importante en el proceso de legitimación, diferenciando el "integrador" del "meramente asociativo". La diferencia se marca en si la gente siente que pertenece junta a una comunidad Gemeinschaft o si ve sus vínculos con los demás como un lazo contractual, algo más exterior y menos comprometedor Gesellschaft (Ricoeur 1994:219). En este marco la desigualdad entre hombres y mujeres se espacializa y constituye en un medio de dominación.

Las formas y características en que se produce espacio geográfico por parte de las mujeres se realizan dentro del patriarcado (Delgado Mahecha, 2003).

Algunos interrogantes que surgen son: ¿Cómo se interpretaron y comentaron estos sucesos dentro de una semiótica androcéntrica? ¿Cuáles son los intersticios en los que se filtró la mirada de las mujeres sobre su historia y su presente? Los feminismos lo han considerado un tema de interés y de discusión, entendiendo que la cultura se crea, recrea y almacena, se guarda a partir de mandatos sociales y familiares aprendidos, e insistentemente enseñados, con distintos grados de violencia 
física y/o moral (Di Lisia, 2007). El tiempo y la memoria de las mujeres muchas veces aparecen articulados con sentidos preexistentes dados por el orden patriarcal y se elaboran a partir de esas asociaciones. En ese orden se yuxtaponen memorias femeninas que emergen, subterráneas y subalternas, confrontando con las memorias oficiales, los olvidos y recuerdos prescriptos.

Retomando las conceptualizaciones que abrevan en el psicoanálisis, los especialistas (Tapia Paniagua y Pérez Vélez, 20II) han considerado que, desde el punto de vista del psiquismo, cuando una experiencia difícil por ser dolorosa o vergonzosa no se introyecta elaborativamente, se convierte en trauma, el cual queda congelado y encriptado implicando no solo una parte sino todo el psiquismo de la persona y se constituye en el elemento organizador de su vida. Esa experiencia se transforma en lo innombrable y amenazante y será objeto de situaciones vividas como extrañas por las mujeres de las generaciones siguientes. Cuando se trabajan psicoanalíticamente estas sensaciones o síntomas la experiencia puede ser rejuzgada y el deseo liberado por las descendientes.

Las palabras que no pudieron pronunciarse y las escenas que no pudieron ser rememoradas, las lágrimas que no pudieron ser vertidas son conservadas en secreto. La necesidad del secreto no proviene de la vergüenza del sujeto, sino de la vergüenza del objeto de amor (el padre o madre, o antepasado), que hizo vivir la experiencia como secreta y vergonzosa (Tapia Paniagua y Pérez Vélez, 20Iı:50).

Los encriptamientos tienen un papel importante en la génesis de diversos trastornos mentales como la depresión, y enfermedades psicosomáticas, etc. Se denomina "fantasma" a los efectos que los secretos de un progenitor producen en sus descendientes. Estas consideraciones son sumamente importantes cuando consideramos que los efectos de las acciones violentas de guerras, violaciones, trata de personas, desplazamientos forzados, desterritorializaciones, ejercidos sobre mujeres o niñas que los reciben, se proyectan hacia las generaciones siguientes. La obligación de asistencia a las víctimas es por lo tanto indelegable por parte de los estados y organismos internacionales y no sólo debe ser material sino de contención psíquica individual y grupal continuada en el tiempo.

Interesado en el fenómeno de la transmisión psíquica en la etiología de las neurosis, Freud ya advertía que cada persona tiene un aparato psíquico capaz de corregir las deformaciones que otra le impone a sus emociones. De enorme interés resulta en estas cuestiones el documental Los tatuajes de la abuela de Suzanne Khardalian 
(2012), nacida en Líbano y afincada en Suecia, quien indaga en las marcas ocultas en las mujeres de su propia familia.

La abuela Khanoum no era como las demás. Desde mi infancia, la recuerdo como una mujer malvada, que despreciaba el contacto físico y nunca demostraba cariño. Usaba guantes para ocultar las manos y tatuajes que guardaban su secreto. Esta consecuencia nefasta es apenas uno de los pliegues del genocidio que permanecen ocultos. Me costó demasiado romper el muro de silencio y blanquear el tema, incluso en mi propia familia, ¿por qué estas mujeres sienten vergüenza por algo de lo que no han sido culpables? Sin embargo, aprendí a comprender su cerrazón. El dolor y el pudor vulnerado han sido devastadores sobre estas víctimas (Khardalian , 20I2).

Suzanne Khardalian presentó su documental en Buenos Aires en el mes de mayo del año 2012. La cineasta reflexionaba entonces sobre los crímenes de lesa humanidad y las huellas en el cuerpo, la psiquis y la memoria transgeneracional encarnada en las descendientes mujeres. Antes de ese documental no había tratado el tema de género relacionado con esa catástrofe humanitaria, pero cierta vez que se encontró en Estocolmo con algunas de las mujeres que habían sido víctimas del exterminio en Ruanda, relacionó esas palabras con las masacres armenias y asumió que había muy poco escrito sobre las mujeres en esa situación.

"De eso no se habla y no cabe preguntar", parecía la consigna tácita. Lo cierto era que muchas de esas mujeres estaban tatuadas y habían dado a luz después de haber sido violadas en matrimonios forzados. El arduo proceso de readaptación también debió contemplar la recuperación de la identidad (las habían rebautizado) y de las tradiciones religiosas, tras ser islamizadas a la fuerza. De todas maneras, casi todas las mujeres tatuadas nunca se animaron a revelar esta cuestión dolorosa a sus seres queridos, tan avergonzadas como temerosas del rechazo y la discriminación de su círculo familiar y social (Ibid).

Daniela Sena Bello (20I2), quien analizó el film desde una perspectiva psicoanalítica, afirma que la búsqueda de Suzanne se inserta en una cadena humana, en una genealogía, en tanto que el linaje nos construye, nos otorga algunas certezas, nos erige como sujetos genealógicos.

Tras un largo recorrido por la voz y gestos de las mujeres de la familia, "cámara al hombro" Suzanne desencripta el secreto, transitando por geografías extrañas y tiempos lejanos, que son presentificados, 
Las tribus turcas, kurdas y árabes son las que hacían los tatuajes a las mujeres, niñas y jóvenes adolescentes entre 6 y 16 años. Cuando las secuestraban las tatuaban para identificarlas como parte de alguna de estas tribus, porque existía la costumbre de robar mujeres entre las mismas tribus. Era fácil secuestrarlas antes porque eran consideradas como un objeto que valía dinero y que servían para satisfacer distintas necesidades. Para cada tribu había tatuajes específicos y para ellos estos dibujos eran muy bonitos. Pero los tatuajes no son parte de la tradición armenia. No es algo lindo para nosotros. Para mí, cuando era niña, eran señales feas y por cierto estigmatizantes (Ibid.).

A partir de las entrevistas realizadas a miembros de la segunda, tercera y cuarta generación, he podido reconocer un poder de resiliencia importante en muchas de ellas (Varela, 2009).

Asia, una mujer de mediana edad, vivió durante toda su infancia y adolescencia en la Armenia soviética y tras la caída del muro emigró con su familia a la Argentina. En junio del año 2004 la entrevisto, entonces aparecen en ella dos memorias yuxtapuestas referidas a los desplazamientos: el biográfico, saliendo en un contexto de guerra (Armenia se encontraba en ese entonces en guerra con Azerbaiyán) y el de su abuela, relativo a los sucesos de genocidio. Ella recuerda:

Mi abuela siempre lo contaba y lloraba. La hermana de mi abuela era ginecóloga y la esposa del Pasha iba a tener un hijo con ella entonces la pudo salvar, le ayudó a cruzar el río Arax, pero el resto de la familia fue asesinada. Llevó la Biblia, la ató a su estómago y con ayuda de Dios pudieron salir.

Cuando pregunto a Asia qué significa para ella Armenia y con qué ideas conecta la palabra, se levanta, corre, me alcanza una foto de la estatua de David de Sasún (héroe mítico) que descuelga de la pared; también asocia el término con Echmiazín y la iglesia de Ani y con el Monte Ararat.

Lika, también migrante reciente, me responde cuando la entrevisto sobre aquellos recuerdos y sobre el posicionamiento de su padres acerca del tipo de transmisión a los más pequeños y las dificultades para su elaboración: "Mis padres prohibieron en el colegio que me hablen del genocidio, porque era cruel para una niña chiquita".

Los padres de Lika son intelectuales, el padre profesor de francés y la madre médica, los recuerdos que ella trae a su memoria se refieren a la época de su infancia. 
Por su lado Anie Kalaidkian, quien trabaja con sobrevivientes setenta y ocho años después de los sucesos para ver los efectos en las generaciones posteriores (residentes en EE.UU.) cuenta que ella partió de una serie de preguntas frente a lo traumático: ¿Qué les pasó? Entonces respondieron que sufrieron una especie de destrucción vital (vidas, propiedades, lugar social que ocupaban, sufrimiento emocional). ¿Qué tipo de dolor persistía luego de tanto tiempo? Lxs sobrevivientes dijeron que, lo que más les dolía era haber presenciado el asesinato de un ser amado, cosa que siguen recordando recurrentemente en las pesadillas, la separación de sus seres queridos, la destrucción de los hogares y las marchas por el desierto, el hambre y la sed y la simulación de fusilamientos. Y frente a las posibilidades de elaboración y superación, se les preguntó a qué habían recurrido para soportar los recuerdos. Entonces las respuestas más frecuentes fueron: en primer lugar la ayuda religiosa y espiritual y el apoyo grupal, y en segundo lugar la atención categórica puesta en el trabajo, como eje organizador de la vida.

Algunas mujeres, que formaron parte de los contingentes de desplazadxs, pudieron enfrentar mandatos ancestrales y proponerse como proyecto de vida trocar el luto en esperanza y reconstruir una pertenencia identitaria en la Argentina (Varela; 2004). Tal la historia de Lusín (Luna) que reconstruyen, a mi pedido, su hija y su nieta en enero del 2005 :

Lusín era oriunda de la ciudad de Bolú, provincia armenia de Turquía. Nació el 20 de julio de 1909. Tras los trágicos sucesos de 1915, su madre la esconderá en casa de una familia turca de su confianza.

Una mañana fue a la plaza del pueblo y vio a un grupo de hombres armenios colgados, esto le provoca una fuerte impresión y fiebre muy alta, de la que se recuperó con el tiempo.

Lusín fue "casada"por determinación familiar con un joven que ya residía en Argentina y viajará sola hacia acá [...]. El joven, su futuro marido, era una persona, según relató siempre Lusín, muy dominada por su madre. Siempre fue, y así la recordamos sus hijas y nietos, una mujer muy libre, con mucha iniciativa e independiente. Esta situación le resultaba por cierto muy difícil de sobrellevar.

Sumamente incómoda con la situación, que se sumaba a otras que la sofocaban bajo el dominio de una madre posesiva, decidió escaparse; pero sólo conocía el tranvía que pasaba por la puerta. Lo tomó, se llevó consigo sus pocas pertenencias y las joyas que le habían regalado (la familia del novio) con motivo del compromiso, esto último lo realizó con la intención de devolverlo ante testigos y que la familia de su novio no la acusara de robar las alhajas, y así fue como lo hizo.[...] A todo esto su foto fue 
publicada en los diarios, se la buscó en el río, pensando que podría estar ahogada, y tras una búsqueda intensa madre e hijo la encontraron en donde siempre había permanecido desde su huida [...

$\mathrm{Al}$ año conoció, junto a un grupo de paisanos armenios que frecuentaba, a su futuro marido, el señor Hovannes Havnichian, con quien contrajo matrimonio, sin poseer vivienda, ni muebles, pero con la ayuda de un grupo de amigos que les prestaron todo para la ocasión.

Vivieron en Barracas muchos años y fueron queridos por los vecinos que habían acriollado el nombre de Lusín, como en el caso de otros armenios, según lo que les "sonaba al oído", por eso la llamaban Doña Lucía [... Con Hovannes tuvieron tres hijas, Ema, María e Isabel , que le dieron seis nietos, de sus siete bisnietos llegó a conocer tres. Lusín falleció en la ciudad de Avellaneda en el año I990.

Una de sus bisnietas, hoy joven estudiante de arte en Buenos Aires, se llama Celeste Lusín en su memoria. La capacidad de resiliencia para el caso de Lusín le permite transmitir una memoria activa, en la que el peso del trauma no obture la capacidad transformadora. Avtar Brah aporta reflexiones en las que enfatiza las diversidades personales en el marco de una experiencia colectiva, anclando la teoría con su práctica social, al ser una inmigrante de origen oriental instalada en occidente, sostendrá que:

De hecho, la "experiencia" es un proceso de significación que es la condición principal para la constitución de lo que llamamos "realidad". De ahí la necesidad de volver a hacer énfasis en la noción de experiencia [... como una práctica de dar sentido, tanto simbólica como narrativamente; como una lucha entre las condiciones materiales y el significado. El mismo contexto puede producir varias "historias" colectivas distintas, biografías que se diferencian tanto como se vinculan - a través de especificidades contingentes. A su vez, al articular las prácticas culturales de los sujetos así constituidos, las "historias" colectivas contingentes quedan marcadas con nuevos y variables significados (Brah, 20II:144/146).

\section{Conclusiones}

El recorrido histórico y presente, con la apoyatura de distintos testimonios documentales y orales, ha permitido confirmar que la condición de mujeres desplazadas, en situaciones límite de violencia, condicionará sin duda las subjetividades y será 
ineludible la transmisión desde el gesto, la palabra o el silencio a las siguientes generaciones. Sin embargo la tramitación personal que cada víctima realice, imprime a la experiencia significaciones propias. La experiencia frente a situaciones límite, aunque colectiva, tendrá la posibilidad de ser resignificada si las condiciones biográficas y subjetivas lo permiten. En instancias de este tipo, el rol de los estados y de los organismos internacionales no puede limitarse a facilitar el traslado de las víctimas, sino que se requiere de un acompañamiento posterior destinado a facilitar la elaboración de síntomas y emociones asociadas con la pulsión de vida y evitar los efectos persistentes de los traumas sociales en las nuevas generaciones.

\section{Bibliografía}

Augé, M.

1996 Los "no lugares". Espacios del anonimato. Una antropología de la sobremodernidad, Gedisa, Barcelona.

Bertaux, D.

1994 "Les transmissions en situation extrême", en Générations et filiation, Communications, núm. 5, París, pp. 73-102.

Bock, G.

I993 "Políticas sexuales nacionalsocialistas e historia de las mujeres", en Georges Duby y Michelle Perrot (dirs.), Historia de las mujeres en Occidente, t. 9, Taurus, Madrid.

Brah, A.

20II Cartografías de la diáspora. Identidades en cuestión, Traficantes de sueños (Mapas, 30), Madrid, en <http://www.traficantes.net/sites/default/ files/pdfs/Cartograf\%C $3 \%$ ADas\%2ode\%2ola\%2odi\%C3\%Aispora-TdS.pdf $>$. [9 de mayo de 20I4].

Bruneau, $M$.

1994 “Espace et territoires de diasporas", en L'Espace Géographique, Montpellier, vol. 23, núm. I, París, pp, 5-18.

Delgado Mahecha, $\mathrm{O}$.

2003 Debates sobre el espacio en la geografía contemporánea, Universidad Nacional de Colombia, Unibiblos, Bogotá.

Di Lisia, H.

2007 "Género y memoria", La Aljaba, vol Ix, unLPam, pp. I4I-I66, en Asociación Uruguaya de Psicoanálisis de las Configuraciones Vinculares, 
Montevideo, disponible en internet: <http://www.scielo.org.ar/scielo. php?pid=Si669-57042007000100007\&script $=$ sci_arttext $>$ [enero de 20I4].

Freud, $\mathrm{S}$.

20II [I9I6-I9I7] Conferencias de introducción al psicoanálisis, Amorrortu, Buenos Aires.

Grinberg, L. y Grinbeg, R.

I996 Migración y exilio, Estudio psicoanalítico, Buenos Aires, Biblioteca Nueva.

Lindón, $\mathrm{A}$.

2012 "Corporalidades, emociones y espacialidades: hacia um renovado betweenness". RBSE - Revista Brasileira de Sociologia da Emoção, v. II, núm. 33, pp. 698-723, Dezembro de 2012. Disponible en internet: $<$ http://www.cchla.ufpb.br/rbse/RBSEvin33dez2012\%2ocompleta. pdf $>$, [enero de 2014].

Lindón, A. y D. Hiernaux.

2010 "Compartir el espacio: encuentros y desencuentros de la Geografía Humana y las Ciencias Sociales”, en: Alicia Lindón y Daniel Hiernaux (dirs.), Los giros de la geografía bumana: tendencias y horizontes, Anthropos-UAmi, Barcelona, pp. 27I-297.

Monk, Janice \& Susan Hanson

I989 “Temas de geografía feminista”, en Documents d’Anàlisi Geogràfica, I4, pp. 3I-50.

Mudrovcic, $\mathrm{M}$

2003 "Alcances y límites de perspectivas psicoanalíticas en historia", en DIANoIA, vol. XCViII, núm. 50, mayo, México.

Nora, P.

I984 "Entre mémoire et histoire", en Les lieux de mémoire, t. I, La Republique, Bibliotheque ilustrée des histoires, París.

ONU

1949 Protocolos Adicionales al Cuarto Convenio de Ginebra Pellegrino, G. et al.

I983 “Representations du territoire et identité, en Espaces et Culture, Georgi, St-Saphorin.

Ricoeur, P.

1994 Ideología y utopía, Gedisa, Barcelona. 
Sena Bello, D.

2012 Trabajo Final Seminario Pareja II: Los tatuajes de la abuela. Disponible en internet: <http://aupcv.org.uy/vincular/wp-content/uploads/2012/r2/ TRABAJO- FINAL-DE-DANIELA-SENA.pdf>

Sirouyan, Cristian

2012 "Mujeres armenias tatuadas, las marcas de un dolor oculto", en Clarín, I9 de mayo de 2012. Disponible en internet: <http://www.clarin.com/ mundo/Mujeres-armenias-tatuadas-marcas-oculto_o_703729723. html $>$ [enero de 20I4]

Tapia Paniagua, M. y N. Pérez Vélez Mendoza

20II "La transmisión transgeneracional del psiquismo", en Uaricha, Revista de Psicología, 8(16), pp. 45-52.

Varela, B.

2009 Geografías de la memoria. Lugares, desarraigos y reconstitución identitaria en situación de genocidio, Universidad Nacional de La Plata, EDULP, La Plata.

2004 "De Armenia a la ciudad de Buenos Aires: la reconstrucción del lugar comunitario a escala local", en: Les Cabiers ALHim Amerique Latine Histoire et Memorie, núm. 9, Migrations en Argentine (M. R. Cozzani, coord.) Université de Paris 8, Francia.

\section{Testimonios}

Documentos históricos

Abrahamian, Y.

2010 "Entrevista a Yelena Abrahamian, sobreviviente del genocidio armenio", en Armenia On Line, publicado el 19-7-I2.

Atkinson,T.

I986 "Informe de Tacy W. Atkinson, misionera norteamericana, al señor James L. Barton, Secretario de la American Board of Commissioners for Foreign Missions, II-4-I9I8", en P. Ohanian, Turquía, Estado genocida 1915-1923. t. I, Documentos, Akian, Buenos Aires, p.374.

Cold, E.

I986 "Informe de Edith M. Cold al American Committee for Armenian and Syrian Relief, 17-I2-I915”, en P. Ohanian, Turquía, Estado genocida 19151923, t. I, Documentos, Akian, Buenos Aires, p.405. 
Gage

I986 "Declaración de la señorita Gage, ciudadana norteamericana, viajera a través de Turquía, a la embajada de los Estados Unidos en Constantinopla, registrada en el Departamento de Estado en Washington”, en P. Ohanian, Turquía, Estado genocida 1915-1923, t. I, Documentos, Akian, Buenos Aires, p.III.

Holt, T.

I986 "Informe de la Srta. Holt,de la Misión Norteamericana de Adabazar a la Revista The New Armenia de Nueva York, fechado el 24 de sept. de I9I5", en P. Ohanian, Turquía, Estado genocida 1915-1923, t. I, Documentos, Akian, Buenos Aires, p.302.

Schafer, $\mathrm{P}$.

I986 "Informe de la enfermera suiza al señor Henry Morgenthau, Embajador de los Estados Unidos de Norteamérica, fechado el I6 de noviembre de I9I5", en P. Ohanian, Turquía, Estado genocida 1915-1923, t. I, Documentos, Akian, Buenos Aires, p.389.

Entrevistas realizadas por la autora a descendientes de familias desplazadas: Like, Asia, Margarita y Celeste.

Realizadas en Buenos Aires, 2003-2005. 